\title{
Progressive Cribriform and Zosteriform Hyperpigmentation along with Vitiligo
}

\author{
Yu Han, Jianmin Chang* \\ Department of Dermatology, Beijing Hospital, National Center of Gerontology, Beijing, China \\ Email: *changjm0417@126.com
}

How to cite this paper: Han, Y. and Chang, J.M. (2017) Progressive Cribriform and Zosteriform Hyperpigmentation along with Vitiligo. Journal of Cosmetics, Dermatological Sciences and Applications, 7, 77-81.

https://doi.org/10.4236/jcdsa.2017.71008

Received: February 4, 2017

Accepted: March 10, 2017

Published: March 13, 2017

Copyright $\odot 2017$ by authors and Scientific Research Publishing Inc. This work is licensed under the Creative Commons Attribution International License (CC BY 4.0).

http://creativecommons.org/licenses/by/4.0/

\begin{abstract}
Background: Progressive cribriform and zosteriform hyperpigmentation $(\mathrm{PCZH})$ is a disorder of pigmentation. Although several cases of PCZH have been reported, cases that associated with vitiligo have not been published in the past. Aim: We report the case to reveal the interesting mosaicism reflecting on the skin. Case Presentation: This case presents a phenomenon of the coexistence of hyperpigmentation and depigmentation arranged in unilateral and symmetric distribution in one patient. Conclusion: The aetiology of the pigmental disorders is still unknown. The linear nature of the pigmented bands probably reflects the clonal migration and proliferation of embryonic melanoblasts, so somatic mosaicism that develops during embryogenesis appears to be the underlying aetiology, which is leading to proliferation and migration of two mixed populations of melanocytes with different potential for pigment production.
\end{abstract}

\section{Keywords}

Hyperpigmentation, Vitiligo, Mosaicism

\section{Introduction}

PCZH and vitiligo are both pigmental disorders. Under some circumstances, they happen to the same body. In this case, a rare presentation that hyperpigmentation combined with depigmentation followed Blaschko's lines is reported.

\section{Case Report}

A 13-year-old boy who had been suffered from vitiligo for three years came to our hospital for follow-up on December 15th, 2015. Three years before, in our hospital, he had been diagnosed with segmental vitiligo considering the depigmentation on the dorsal surface of his left hand, two years later, the lesion spread 
to the left upper extremity, chest and right scrotum, and was considered as a mixed type of vitiligo.

After being treated with vitamin tablets and glucocorticoid ointment, the patient's condition improved one month later, then he received narrow-UVB treatment. This time he came for follow-up of vitiligo. Through physical examination, we found some hyperpigmented macules on the left side of his back, his mother recalled that it appeared a year ago but had been ignored, and the boy denied neither any obvious causes nor any preceding symptoms such as erythema or vesicle formation before that.

He had no history of internal diseases, nor any abnormality was detected at birth. His mental and physical development was normal, his family reported no history of skin diseases and all routine laboratory tests were normal.

Physical examination revealed linear, cribriform, brown macular pigmentation arranged in a zosteriform pattern on the left back (Figure 1), which is symmetrical to the irregular depigmented macules on the anterior surface of the chest (Figure 2).

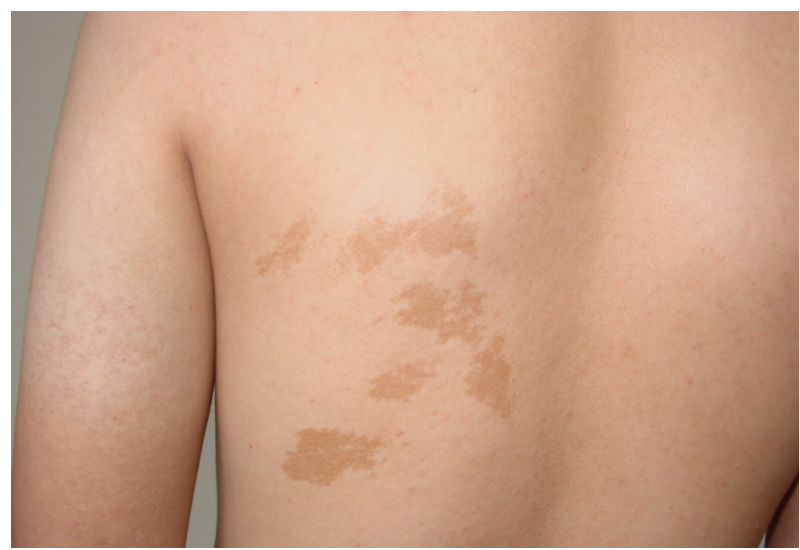

Figure 1. Linear, cribriform, brown macular pigmentations arranged in a zosteriform pattern on the left back.

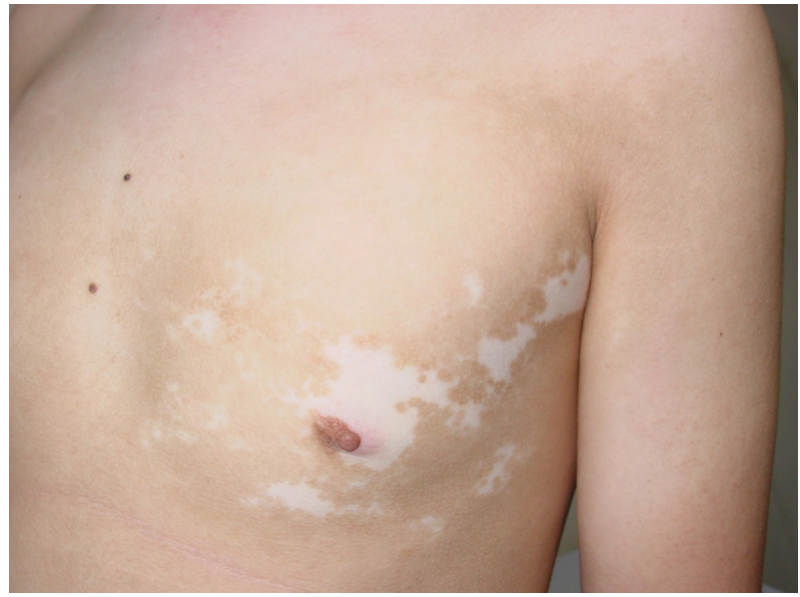

Figure 2. Irregular depigmented macules on the anterior surface of the chest, symmetrical to the lesions on the rear side. Repigmented skin paddles in it can be figured out. 
We diagnosed it as progressive cribriform and zosteriform hyperpigmentation along with vitiligo. As the patient's guardian concerned more about the depigmented lesions, they finally rejected the limited curative effect of laser treatment for the hyperpigmented parts. The boy continued to receive the narrow-UVB treatment of vitiligo as we suggested.

A follow-up was made a year later, there was no expansion of the hyperpigmented lesions and a little improvement of the vitiligo on the chest.

\section{Discussion}

Progressive cribriform and zosteriform hyperpigmentation (PCZH) was first described by Rower et al. [1] in 1978, and five diagnostic criteria were suggested. It's characterized by swirls and streaks of macular pigmentation following the lines of Blaschko with a sharp midline cut-off and asymptomatic in nature, and always presenting in the second decade of life as this case shows. There was no significant difference between male and female patients in prevalence, age of onset, or duration of lesions [2]. Skin biopsy reveals increased pigmentation in basal keratinocytes and a few dermal melanophages, no nevus cells were present [3]. In this case, we should distinguish PCZH from Café-au-lait, the latter can combined with abnormalities such as Albright syndrome, neurofibromatosis, tuberous sclerosis, and characterized by uniformly tan macules.

In 1992, dermatologists suggested that PCZH should be considered to be the later onset type of linear and whorled nevoid hypermelanosis. Because they both show the same histopathological presence of basal hyperpigmentation, with no increase in numbers of melanocytes or pigmentary incontinence [4]. The term linear and whorled nevoid hypermelanosis (LWNH) was named by Kalter et al. [5] in 1988, it has nearly the same clinical feature as PCZH but not always localized, and occurring within the first weeks of life. While there is still mild difference between the two-LWNH is more likely to be associated with abnormalities especially the diffuse type when compared with PCZH [6]. We can only find one case of PCZH associated with polythelia [7] has been reported up to now.

It's very worthy of study that both hyperpigmentation and depigmentation could happen to the same person. Previously we have reported a case that depigmented nevi presented with Café-au-lait [8]. The aetiology of the pigmental disorder is still unknown. The linear nature of the pigmented bands probably reflects the clonal migration and proliferation of embryonic melanoblasts, so somatic mosaicism that develops during embryogenesis appears to be the underlying aetiology [9]. In 1996 Nehal et al. [10] studied 54 patients with both hypopigmentation and hyperpigmentation following the lines of Blaschko. It was postulated that developmental somatic mosaicism leading to proliferation and migration of two mixed populations of melanocytes with different potential for pigment production was the cause of these abnomalies. Currently, most of the authors are of the view that term "pigmentary dysplasia with genetic mosaicism" or "pigmentary mosaicism" is a more apt term encompassing different phenotypic expressions of common pathogenic process caused by genetic mosaicism 
that specifically disrupt expression of pigmentary genes [11].

At last, the parents rejected the punch biopsy of the hyperpigmented skin, so we haven't got the histopathological proof. It's really fantastic that the mosaic phenomenon reflects on the skin, and we should do more to illustrate the black and white situation.

\section{Conclusion}

It's very worthy of studying that different pigmental disorders could happen to the same person. The aetiology is still unknown. The linear nature of the pigmented bands probably reflects the clonal migration and proliferation of embryonic melanoblasts, so somatic mosaicism that develops during embryogenesis appears to be the underlying aetiology, which is leading to proliferation and migration of two mixed populations of melanocytes with different potential for pigment production.

\section{References}

[1] Marvin Rowe, J., Carr, R.D. and Lowney, E.D. (1978) Progressive Cribriform and Zosteriform Hyperpigmentation. Archives of Dermatology, 114, 98-99.

https://doi.org/10.1001/archderm.1978.01640130062018

[2] Cho, E., Cho, S.H. and Lee, J.D. (2012) Progressive Cribriform and Zosteriform Hyperpigmentation: A Clinicopathologic Study. International Society of Dermatology, 51, 399-405. https://doi.org/10.1111/j.1365-4632.2011.04988.x

[3] Choi, J.C., Yang, J.H., Lee, U.H., et al. (2005) Progressive Cribriform and Zosteriform Hyperpigmentation-The Late Onset Linear and Whorled Nevoid Hypermelanosis. European Academy of Dermatology and Venereology, 19, 638-639. https://doi.org/10.1111/j.1468-3083.2005.01201.x

[4] Iijima, S., Naito, Y., Naito, S., et al. (1987) Reticulate Hyperpigmentation Distributed in a Zosteriform Fashion: A New Clinical Type of Hyperpigmentation. British Journal of Dermatology, 117, 503-510. https://doi.org/10.1111/j.1365-2133.1987.tb04931.x

[5] Kalter, D.C., Griffiths, W.A. and Atherton, D.J. (1988) Linear and Whorled Nevoid Hypermelanosis. Journal of the American Academy of Dermatology, 19, 1037-1044. https://doi.org/10.1016/S0190-9622(88)70269-8

[6] Vito Di Lernia, M.D. (2007) Linear and Whorled Hypermelanosis. Pediatric Dermatology, 24, 205-210. https://doi.org/10.1111/j.1525-1470.2007.00387.x

[7] Schepis, C., Alberti, A., Siragusa, M., et al. (1999) Progressive Cribriform and Zosteriform Hyperpigmentation: The Late-Onset Feature of Linear and Whorled Nevoid Hypermelanosis Associated with Congenital Neurological, Skeletal and Cutaneous Anomalies. Dermatology, 199, 72-73. https://doi.org/10.1159/000018187

[8] Chang, J.M. (2013) A Case Report: Depigmented nevi along with café-au-laitspots. The Chinese Journal of Clinical Dermatology, 42, 421.

[9] Akiyama, M., Aranami, A., Sasaki, Y., et al. (1994) Familial Linear and Whorled Nevoid Hypermelanosis. Journal of the American Academy of Dermatology, 30, 831-833. https://doi.org/10.1016/S0190-9622(94)70090-7

[10] Nehal, K.S., PeBenito, R. and Orlow, S.J. (1996) Analysis of 54 Cases of Hypopigmentation and Hyperpigmentation along Lines of Blaschko. Archives of Dermatology, 132, 67-70. https://doi.org/10.1001/archderm.1996.03890340027005 
[11] Goyal, T. (2013) Progressive Cribriform and Zosteriform Hyperpigmentation: Where Are We at Present? Indian Dermatology Online Journal, 4, 264-266.

https://doi.org/10.4103/2229-5178.120633

Submit or recommend next manuscript to SCIRP and we will provide best service for you:

Accepting pre-submission inquiries through Email, Facebook, LinkedIn, Twitter, etc. A wide selection of journals (inclusive of 9 subjects, more than 200 journals)

Providing 24-hour high-quality service

User-friendly online submission system

Fair and swift peer-review system

Efficient typesetting and proofreading procedure

Display of the result of downloads and visits, as well as the number of cited articles Maximum dissemination of your research work

Submit your manuscript at: http://papersubmission.scirp.org/

Or contact jcdsa@scirp.org 